\title{
Lógica Criativa: a construção de mídias digitais para o ensino de matemática
}

\author{
Juscileide Braga de Castro ${ }^{1,3}$ Isabela Oliveira Soares ${ }^{2}$, Eduardo Perdigão de \\ Negreiros Vianna ${ }^{2,3}$, Joyce da Silva Sousa ${ }^{2,3}$
}

${ }^{1}$ Docente da Universidade Federal do Ceará - Faculdade de Educação, Departamento de Teoria e Prática do Ensino (DTPE), Fortaleza - CE - Brasil

${ }^{2}$ Estudantes de graduação da Universidade Federal do Ceará, Fortaleza - CE - Brasil

${ }^{3}$ Membros do Grupo de Pesquisa e Produção de Ambientes Interativos e Objetos de Aprendizagem - PROATIVA, UFC

juscileidedvirtual.ufc.br; isabela.o.soaresegmail.com;

eduardopnvianna@gmail.com; joycesousa @live.com

\begin{abstract}
This paper aims to present a collaborative digital media production project carried out with the undergraduate students in Pedagogy of the Federal University of Ceará (UFC), as part of the Mathematics Teaching discipline. The students used principles of Design Thinking to produce 5 medias that deal with contents such as: algebra, patterns, anthropometric measures, graphs and multiplication situation. The results indicate that the constructionist approach adopted in the project, of learning to do, contributed to the conceptual, theoretical and methodological understanding of the contents worked.
\end{abstract}

Resumo. Este trabalho tem como objetivo apresentar um projeto de produção colaborativa de mídias digitais realizado junto aos estudantes de Licenciatura em Pedagogia da Universidade Federal do Ceará (UFC), como parte da disciplina de Ensino de Matemática. Os discentes utilizaram princípios do Design Thinking para produzir 5 mídias que abordam conteúdos como: álgebra, padrões, medidas antropométricas, gráficos e situação de multiplicação. Os resultados indicam que a abordagem construcionista adotada no projeto, de aprender fazendo, contribuiu para a compreensão conceitual, teórica e metodológica dos conteúdos trabalhados.

\section{Introdução}

A sociedade vem incorporando o uso de mídias nas mais diversas atividades humanas: nos negócios, no entretenimento, na educação. As tecnologias digitais têm chegado às escolas, a partir da disposição de ferramentas como computadores e dispositivos portáteis. Essa conexão entre diversos dispositivos podem propiciar experiências relevantes, pois possibilita o desenvolvimento de projetos interdisciplinares, a geração de dados em tempo real e a interação, como as que podem acontecer, por exemplo, na resolução de problemas colaborativos [Castro e Castro-Filho 2012].

Castro (2016) explica que o uso de dispositivos tecnológicos propicia a utilização de tecnologias mais dinâmicas e interativas, que oportunizam a manipulação de objetos e a observação de resultado, permitindo a construção de significados pelo estudante, o que contribui para a modificação da relação do homem com o 
conhecimento. No entanto, estas modificações requisitam uma reanálise dos processos de ensino, considerando certos pressupostos e teorias, algo que deve ser realizado desde a formação inicial.

É preciso quebrar paradigmas e aproximar os docentes da cultura digital a fim de aperfeiçoar o uso das tecnologias digitais como meios educacionais. A exploração das tecnologias digitais na formação inicial pode contribuir para o desenvolvimento de profissionais com maior capacidade de se adaptarem a diferentes realidades e eficazes em buscar e aprender novas habilidades frente à problemas desconhecidos.

Considera-se, uma possível abordagem, a aprendizagem baseada no construcionismo, da qual compartilha a visão de que a construção das estruturas de conhecimento acontece por meio da internalização progressiva de ações e que isso se dá em um contexto em que o aprendiz está conscientemente comprometido com a atividade, seja ela qual for [Papert 2008; Papert e Harel 1991].

Diante do exposto, este artigo tem como objetivo apresentar um projeto de produção colaborativa de mídias digitais realizado junto aos estudantes de Licenciatura em Pedagogia da Universidade Federal do Ceará (UFC), como parte da avaliação da disciplina de Ensino de Matemática.

Nas sessões seguintes, apresentar-se-á os procedimentos metodológicos, dos quais descreverão o contexto, os sujeitos e os materiais utilizados. Em sequência serão dispostos a discussão sobre o processo adotado durante a aula, seguida das considerações finais.

\section{Contexto e procedimentos metodológicos da investigação}

Esta investigação surgiu a partir das experiências vivenciadas na disciplina de Ensino de Matemática do Curso de Pedagogia da Faculdade de Educação (FACED), durante o semestre 2017.1, o qual teve 27 estudantes matriculados. A disciplina de Ensino de Matemática é a única disciplina obrigatória de matemática do curso, com carga-horária semestral de 96h/a, o equivalente a 6 créditos. Contudo, embora esta disciplina seja importante para a formação destes discentes, 72\% afirmaram ter dificuldades teóricas, didáticas-metodológicas e conceituais em relação à Matemática.

Considerando esta realidade e os sujeitos envolvidos, foi proposto, como atividade final da disciplina, a produção e a análise de mídias (analógicas e digitais) que contemplassem os 4 blocos de conteúdos definidos pelos Parâmetros Curriculares Nacionais de Matemática: Números e operações; Espaço e Forma; Grandezas e Medidas; e Tratamento da Informação [Brasil 1997].

Para atender ao objetivo definido, este trabalho focará na produção colaborativa de mídias digitais, que foi realizada em grupos, tendo sido usado, para a criação das mídias, o Animaker, o Youtube, o Scratch, o editor de texto do Google Drive e o Power Point. A seguir serão descritas as etapas do processo de produção, assim como serão apresentadas algumas das mídias produzidas.

\section{Resultados e Discussões}

O processo de produção de mídias seguiu os princípios do Design Thinking, que contempla métodos e processos para resolução de problemas com teste das soluções. Este processo inclui 4 etapas: [1] imersão - nesta etapa toma-se conhecimento da situação geral, do tipo de problema que se deseja resolver, além das necessidades de todas as partes interessadas no produto final, em especial o cliente-alvo; [2] análise e síntese - considera-se, nesta etapa, os dados recolhidos durante o processo de imersão e as especificações do problema a ser resolvido são delimitadas; [3] ideação - etapa em que busca-se a síntese do problema, sendo lançadas propostas de solução, que são 
anotadas, filtradas e reunidas até se chegar numa proposta final; e [4] prototipação e testes, onde a partir da proposta final se gera um produto puramente funcional que então será testado na sua capacidade de resolver o problema antes de ser finalizado.

Estas etapas não precisam seguir uma sequência linear e podem ser suprimidas ou repetidas, em caso de necessidade. Isto permitiu observar, durante o processo, as estratégias utilizadas pelos alunos na solução dos problemas que surgiam na elaboração do recurso; a reelaboração e a mudança de abordagem metodológica, assim como a apropriação conceitual dos conteúdos abordados.

A princípio os alunos mostraram muita insegurança diante dos desafios em lidar com a produção de mídias digitais, apegando-se, muitas vezes, a metodologias mais instrucionistas e tradicionais de ensino. Porém, em algumas etapas do processo, verificavam a necessidade de remodelarem seus projetos iniciais, o que permitiu que os discentes acrescentassem elementos mais criativos, conceitualmente corretos e com múltiplas representações, por exemplo (Figura 1, 2 e 3). Sobre isso, Castro (2016) explica que recursos que utilizam múltiplas-representações apresentam maior potencial para proporcionar a aprendizagem dos estudantes.

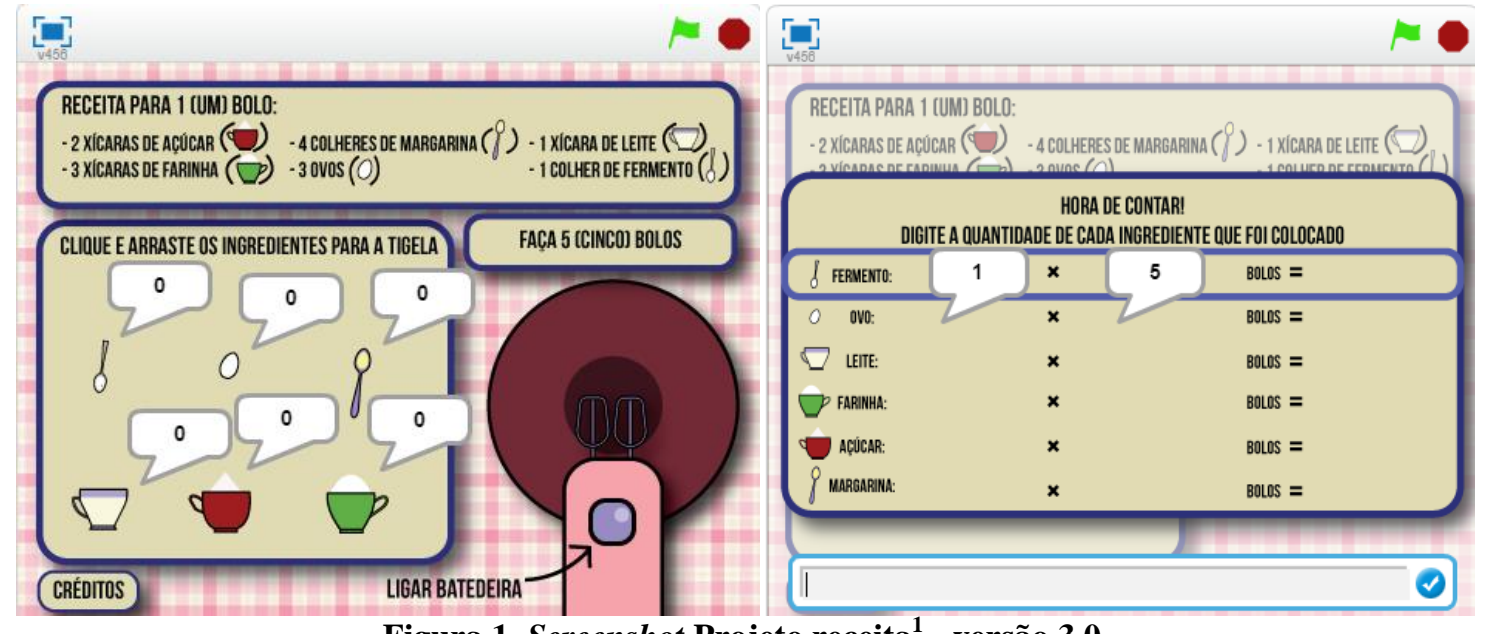

Figura 1. Screenshot Projeto receita ${ }^{1}$ - versão 3.0

A Figura 1 apresenta o print da terceira versão de uma das mídias produzidas em grupo, que tinha como proposta inicial de trabalhar a multiplicação, por meio da tabuada de 3 . As discussões e a prototipação inicial contribuíram para que a equipe verificasse limitações - o recurso não era randômico, apenas arrastar os ingredientes deixava a atividades com o caráter mais aditivo do que multiplicativo - e contribuições a situação de receita de bolo trabalhava com uma relação quaternária com a ideia de proporcionalidade, o uso de diferentes representações (icônica, numérica e tabular) para representar a situação, além da inserção da tabela para incentivar o pensamento multiplicativo.

Numa aproximação com a concepção do construcionismo [Papert 2008; Papert e Harel 1991], foi possível constatar uma melhora nos aprendizados dos discentes, nos aspectos conceituais relacionados às estruturas multiplicativas; metodológicos e teóricos. Os estudantes, movidos pela necessidade em solucionar dúvidas que despontavam no momento em que os mesmos testavam as hipóteses nos protótipos construídos, procuravam os conhecimentos requeridos de modo cada vez mais autônomos. Foram desenvolvidos, ao todo, 5 mídias digitais que abordam conteúdos

\footnotetext{
${ }^{1}$ Disponível em: https://scratch.mit.edu/projects/168435682/
} 
VI Congresso Brasileiro de Informática na Educação (CBIE 2017)

Anais dos Workshops do VI Congresso Brasileiro de Informática na Educação (WCBIE 2017)

como: situação de multiplicação, álgebra, padrões, medidas antropométricas e gráficos (Figuras 1, 2 e 3).

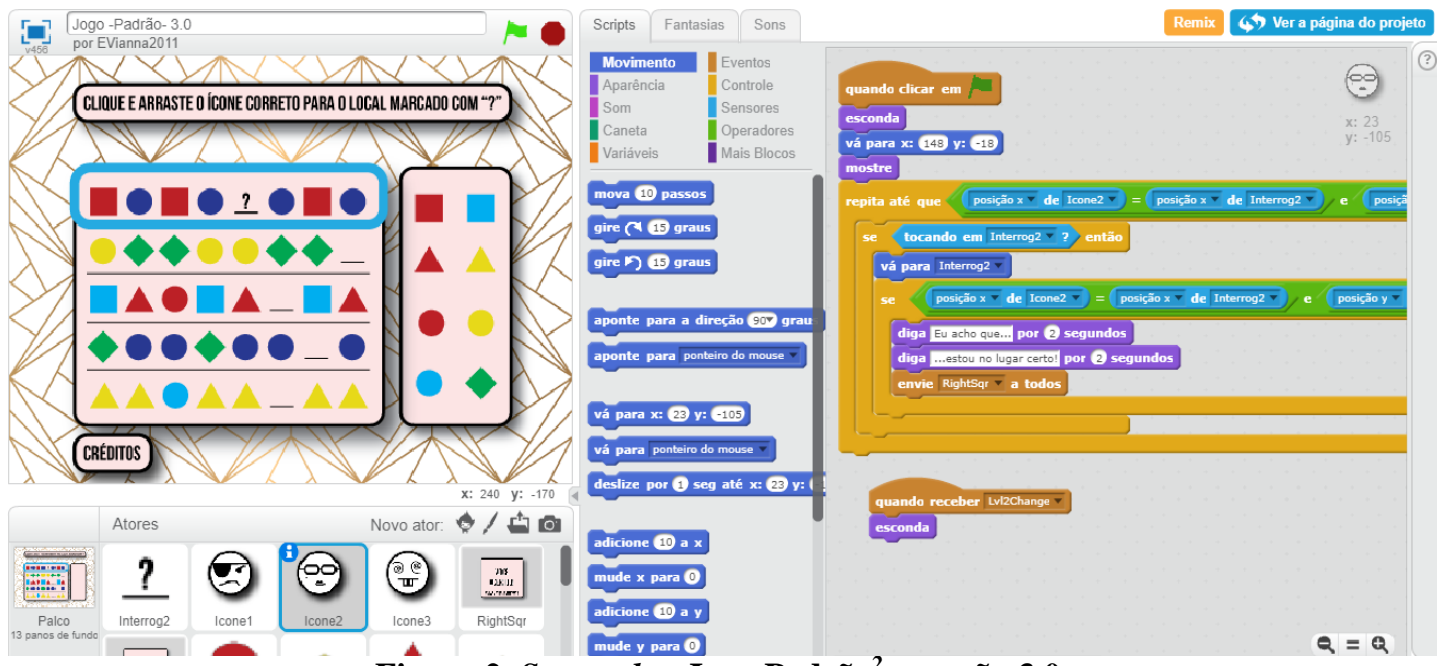

Figura 2. Screenshot Jogo Padrão ${ }^{2}$ - versão 3.0

Na Figura 2 é possível verificar um jogo feito, a partir do Scratch, para o trabalho com padrões, em que é explorado as ideias de regularidade, sequência, sucessão, repetição, ordem, dentre outros; com o uso de diferentes imagens. Estas ideias foram acrescentadas durante processo de elaboração das atividades, à medida que os discentes testavam o recurso.

Na Figura 3 constata-se o vídeo interativo feito no Animaker para o trabalho do Tratamento da Informação, que apresenta características interdisciplinares. $\mathrm{O}$ recurso foi desenvolvido considerando a noção de cadeia alimentar, trabalhada na disciplina de Tópicos de Ciências; e a necessidade de compreensão de informações representadas por meio de gráficos.

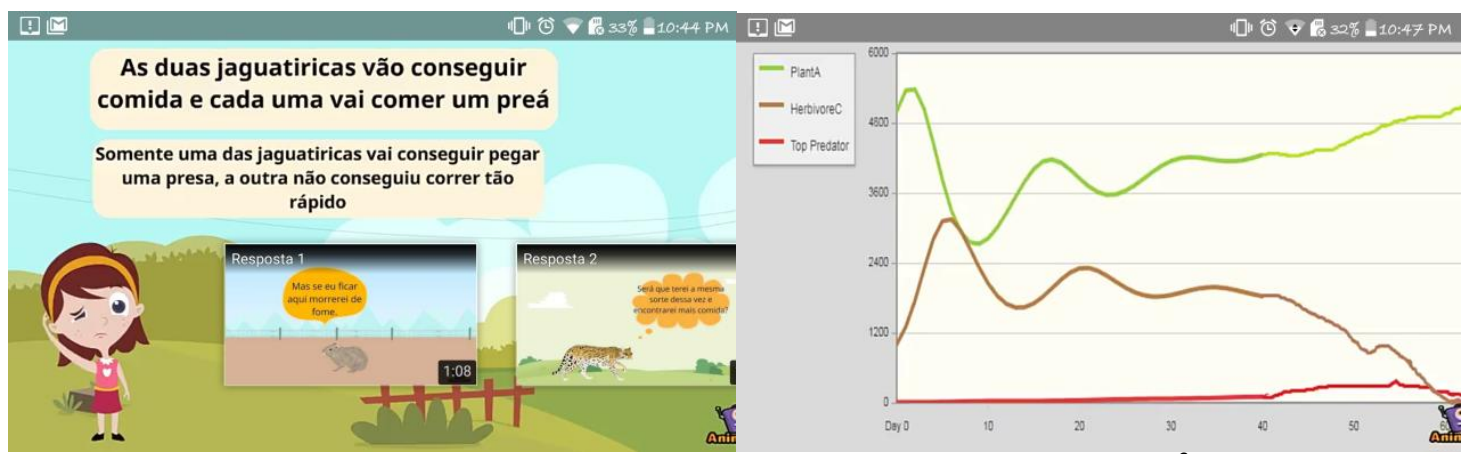

Figura 3. Screenshot do vídeo interativo - Cadeia alimentar ${ }^{3}$

O vídeo interativo permite que o usuário escolha diferentes rumos para a história, com resultados distintos, a partir da opção escolhida, combinando diferentes tipos de representações: textual, icônica e gráfica. A opção da equipe por este tipo de mídia foi justificada pela pouca interação proporcionada pelos vídeos comuns, demonstrando a preocupação da equipe com as questões didáticas.

Ao final do semestre foi organizada a apresentação dos trabalhos, na qual os alunos expuseram o resultado e refletiram acerca do processo vivenciado. A troca de

\footnotetext{
2 Disponível em: https://scratch.mit.edu/projects/168450725/

${ }^{3}$ Disponível em: https://www.youtube.com/watch?v=-0Z2lpNjZeg
} 
VI Congresso Brasileiro de Informática na Educação (CBIE 2017)

Anais dos Workshops do VI Congresso Brasileiro de Informática na Educação (WCBIE 2017)

conhecimentos realizada, nesse momento, permitiu a compreensão das dificuldades e socialização de metodologias. A seguir serão dispostas as considerações finais.

\section{Considerações finais}

Este artigo teve como objetivo apresentar a experiência com o projeto de construção colaborativa de mídias digitais, desenvolvido como parte da disciplina de ensino de matemática do curso de pedagogia na faculdade de educação da Universidade Federal do Ceará no semestre de 2017.1.

A experiência vivenciada permitiu visualizar os ganhos para a aprendizagem de uma metodologia ativa, que coloca o aluno como protagonista do seu próprio processo de aprendizagem. É preciso, portanto, permitir o envolvimento dos discentes na disciplina, permitindo a troca de experiências e saberes, a reflexão, a construção, a pesquisa, a análise e a formulação de métodos próprios para resolver situações matemáticas. Partindo-se destas necessidades, as tecnologias existentes podem auxiliar tanto no ensino, quanto na aprendizagem da matemática.

Em estudos futuros, espera-se possibilitar que as mídias desenvolvidas, como forma de reflexão dos conceitos, metodologias e teorias estudadas ao longo da disciplina de Ensino de Matemática sejam aplicadas e validadas no ambiente escolar.

\section{Referências}

Brasil, MEC/SEF. (1997) 'Parâmetros curriculares nacionais: Matemática'. Brasília: MEC/ Secretaria de Educação Fundamental.

Castro, J. B.; Castro-Filho, J. A. (2012) 'Projeto Um Mundo de Informações: Integração de Tecnologias Digitais ao Currículo Escolar'. In: Congresso Brasileiro de Informática na Educação, 1., 2012, Rio de Janeiro. Anais... Rio de Janeiro: SBC.

Castro, J. B. de. (2016) Construção do conceito de covariação por estudantes do Ensino Fundamental em ambientes de múltiplas representações com suporte de tecnologias digitais. Tese (Doutorado em Educação) - Universidade Federal do Ceará, 2016.

Papert, S. (2008) 'A máquina das crianças: repensando a escola na era da informática'. Porto Alegre: Artmed.

Papert; S; Harell, I. (1991) 'Situating Constructionism'. In Constructionism (S. Papert and I.Harel Eds.). Norwood, New Jersey: Ablex. 